\title{
My Experience to Prevent Hematoma on Hyperhidrosis Surgery
}

\author{
Wen Tsao Ho*1 and Jiun Yit Pan ${ }^{2}$ \\ ${ }^{1}$ Department of dermatology, Ho Wen Tsao Skin Clinic, Taiwan \\ ${ }^{2}$ Department of dermatology, National Skin Centre, Singapore
}

Received: February 21, 2018; Published: February 28, 2018

*Corresponding author: Wen Tsao Ho, Department of dermatology, Ho Wen Tsao Skin Clinic, No. 179, New Taipei city, Taiwan, Tel: 886226084383; Email: varec.clinic@gmail.com

\section{Opinion}

Currently, various techniques are used to prevent hematomas, including drainage tubes, fibrin glue, quilting sutures and tieover dressings [1]. Considered fibrin glue failed to influence the incidence of postoperative seromas on a systematic review of randomized controlled trials. The technique issued by Roh NK did indeed significantly decrease the incidence of hematomas [2]. We have applied this technique in our daily practice and still encountered some hematomas. We tried to solve these problems and would like to share our experiences in this letter. The tie over bandage was crucial for preventing hematomas. The patients were scheduled to remove the tie over bandage on the third day. We found the color was rusty to black instead of reddish, which means the active bleeding might occur mainly in the first 1-2 days and we can deduce that removal of the bandage on the third day is feasible. Although quilting sutures reduced the occurrence of hematomas, we still subsequently found a few hematomas and seromas with a particular presentation in between the quilting sutures after removing the tie-over bondage at 3 days post-operatively.

Once hematomas or seromas were found, we removed the quilting sutures immediately, dislodged old blood clots and cared the wound again. According to our experiences, the situation would be improved completely but wound healing time may be delayed and the risk of partial skin flap necrosis may be increased. Additionally, the scar may appear more obvious. In order to solve these problems, the first method we thought was to increase the number of sutures based on the size of axilla. Sometimes, the number of sutures may be increased twice. This method seems to be able to further decrease the incidence of hematomas and seromas. The second method we used was to make $2-3 \mathrm{~mm}$ incisions by no. 11 blade between the quilting sutures so that subcutaneous blood and transudate could flow out through the incisions. We had published the second method on JPRAS online.
However, some patients still suffered hematomas occasionally due to personal body constitution. After careful observation, we found that oozing occurred more commonly in those patients who had special body constitution while undertaking surgery. Unfortunately, the bleeding point could not be identified during surgery so it was difficult to stop bleeding by electro cauterization. An increase in the number of quilting sutures could possibly solve this situation, but some patients still suffered hematomas or large blood stasis. Therefore, we tried another method, pressing the gauze firmly with our palm on the patient's skin flap and subcutaneous tissue for 20 minutes to enhance coagulation effects after apocrine gland removal and before quilting suture [3]. Accidently, we found that oozing phenomena were significantly improved and the incidence of hematomas was effectively decreased on clinical observation.

\section{Conclusion}

Now I use the following three methods simultaneously to prevent hematomas:

a. Pressing the gauze firmly with the palm over the skin flap for 20 minutes to enhance coagulations.

b. Increasing the number of sutures

c. Making incisions between sutures. Share these three additional methods here, hoping that the incidence of postoperative hematomas could be decreased further.

\section{References}

1. Sajid MS, Hutson K, Kalra L (2012) The role of fibrin glue instillation under skin flaps in the prevention of seroma formation and related morbidities following breast and axillary surgery for breast cancer: a meta-analysis. J Surg Oncol 106(6): 783-795.

2. Rho NK, Shin JH, Jung CW (2008) Effect of quilting sutures on hematoma formation after liposuction with dermal curettage for treatment of 
axillary hyperhidrosis: a randomized clinical trial. Dermatol Surg 34(8): 1010-1015.

\section{(C) 9 This work is licensed under Creative}

Submission Link: http://biomedres.us/submit-manuscript.php
3. Miao-Erh Chang, Shih-Cheng Hsu, Wen-Tsao Ho (2017) Small incisions between quilting sutures for preventing haematoma during hyperhidrosis operations. JPRAS Open 12: 84-86.

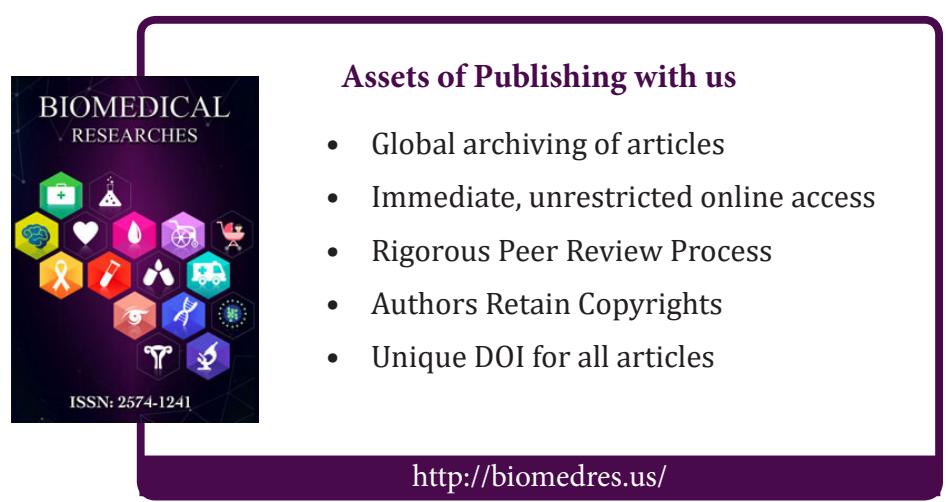

